\title{
Integrated Learning in History Using Babad Banyumas to Improve the Empathy of Fellow Students
}

\author{
Darmawan Edi Winoto $^{1 *}$, Sariyatun $^{2}$, and Warto ${ }^{3}$ \\ ${ }^{1}$ Master of History Education, Universitas Sebelas Maret, Surakarta 57126, Indonesia \\ ${ }^{2}$ Universitas Sebelas Maret, FKIP, Surakarta 57126, Indonesia. \\ ${ }^{3}$ Universitas Sebelas Maret, Faculty of Cultural Science, Surakarta 57126, Indonesia.
}

\begin{abstract}
The article focused on the analysis of Babad Banyumas which is integrated in historical learning contents. The purpose of this integration was an effort to improve the sympathy of fellow students. Practicing this empathy was for the sake of realizing a harmonious friendship. This research was conducted in explorative way due to data collection techniques using observation, interview, document analysis, and questionnaire. The selection of the object was based on its position as a standard text. This paper was based on text analysis with qualitative research. Checklist was used as assessment instrument. Validity was done through discussion and triangulation technique. Data analysis was done through interactive analysis technique based on independent samples t-test using SPSS 15. The results of the study showed that the integrated history of Babad Banyumas could improve the empathy of fellow students.
\end{abstract}

\section{Introduction}

In this globalization era, technology has developed to bring a huge impact on human being and society nowadays. The most important thing is fast, easy, and unlimited way of information society. The information society is a result of the production system globalization, of distribution and use of information. This means that only based on globalization processes and in their wake the information society gets established on a global scale, turns into a world-wide human community [1]. Information technologies in the educational process are of a great importance. However, this practice has not yet been mastered in full in the sphere of culture [2]. Due to educational field, globalization brought a great influence either. Globalization has a significant positive potential and it could help to overcome poverty, reduce inequalities between people, and strengthen cross-cultural, economic, educational and other contacts [3]. Besides, interfaith, intercultural, and cross country interactions have been grown so fast. So, intercultural interaction skill is basically needed to survive in anywhere. Cross-cultural interaction with representatives of various

\footnotetext{
*Corresponding author: ediwinotodarmawan@yahoo.co.id
} 
cultures forms in the personality such qualities as tolerance, empathy, ability to respect and accept other point of view [3].

In the other hand, there is negative impact due to globalization which is the increasing of individualistic. Individualistic caused less solidarity, tolerance, sympathy, and empathy between one and another. Based on several researches, it was showed that tolerance and understanding skill in society have been decreased day by day. Anti social behaviors such as bullying, indifferent, egoistic, and apathetic toward others then appear.

To be able to decrease and prevent those unwanted behaviors, education to enhance the importance of empathy. Education can be used as proper way to overcome modern lifestyle in society nowadays.Under modern conditions educational activity becomes increasingly important for the society, since knowledge is developing faster and tends to become obsolete faster than before [4]. Besides, proper education can reduce any anti social behaviors and enhance pro-social behavior. Recently studied show that empathy training as an essential element in bullying prevention and intervention programs [5]. Education mentioned is paradigm based of education which helps to improve affective and psychomotor skill rather than cognitive aspect. Basically, Eisenberg stated that individual process to show empathy is including affective and cognitive skill.

Empathy (in cognitive or effective aspect) is basically changing in time due to teaching and learning process. A small number of study have examined how empathy levels might change through life. An early study indicated that empathy increased with age for the normal controls during adolescent period, whereas the cases did not. Recently, Dadds measured both cognitive and affective empathy of a group of Australian children and adolescents aged 4-16. The results suggested that cognitive empathy, as judged by parents increased with age, but affective empathy did not [6].

Education with good representative of affective aspect is mostly found in historical learning. Yet, historical teaching and learning at school is brought to national or common learning subjects so that affective or psychomotor aspect could not be taken by student in specific local wisdom. This phenomenon can trigger some differences of perspective and behavior of students in certain areas due to national historical learning. Thus, learning history at school is only aimed to cognitive aspect. It cannot lead to affective aspect of each student properly.

Educational and cultural problems which are connected with globalization can't be solved only by pedagogical means, integration of education and culture, interrelation of education and all subjects of a sociocultural environment are important here [3]. So, learning history integrated on local wisdom is truly needed. Babad Banyumas, as one of local wisdom, consists of values that can encourage student's empathy. Meanwhile, Babad Banyumas can be used as an effective way to behave at school. So, it is effective to be integrated in learning history in order to improve student's empathy.

\section{Literature Review}

Teaching and learning history is an effort in growing values and norms which are included in historical events so that students could learn to be wise in a proper way. Teaching and learning history is a process through values internalisation based on past events, namely origin of theory, genealogy, collective experience, and exemplary of characters in history. This learning process is held to preserve human being to be wise and kind hearted since historical learning tends to produce good quality outpout with comprehension in nation history, examplary in wisdom, and clever character of characters in history [7]. 
Babad, which is well known as traditional historiography, has brought the soul of past time and the thought of human being from past events. Babad is one of meaningful historical's opuses since each event in the past contains a lot of wisdom characters. Babad Banyumas as one of traditional historiography can reflect to five genealogy circle in structure, which consists of Pangiwa history, Majapahit family tree, Banyuamas dynasty family tree, Mertadirejan genealogy, and new family genealogy [8]. Babad Banyumas tells the origin of Banyumas itself.

Empathy is typically conceptualized as a multidimensional construct with both cognitive and affective components. Its cognitive component refers to a person's ability to comprehend another person's emotions (e.g., Hogan 1969); its affective component refers to capacity to experience another person's emotions (e.g., Mehrabian and Epstein 1972). Davis (1983) and Cohen and Strayer (1996) have defined empathy as including the ability to understand and experience how another person feels [5]. Empathy can conduct togetherness. Empathy can also prevent conflict as if we can listen, understand, and feel the related person [9]. In the other hand, empathy is truly related to social awareness. Silvera stated that social awareness describes the ability to recognize culture and values related aspects of different social groups and how these aspects influence individual's actions and behaviour [10].

Empathy, according to its correlation to education, is very important in student learning success. Therefore, empathy contributes to student's achievement and performance in classsroom. Recently research showed that young children with higher levels of empathy (the ability to empathize with others) tend to be less aggressive, more socially adapted and more successful in learning than children with low levels of empathy [11]. Goleman argue that there are 3 indicators of sympathy, (1) listening to other people talk about. It means that the individual can be a good listener. They listen to other people who are talking, (2) Accept others' point of view. It means that more look the problems from the other student's perspective than personal's, (3) Be sensitive to other people's feelings. It means that individual feels what the other people feel about [12].

\section{Method}

The study conducted is using qualitative research method, derived from field research. Sample of research consists of 60 students as experiment class and 60 students of control class. The methods used in collecting data are observation based on behavior, questionnaire, interview, and documentation during teaching and learning process in classroom held, starting from the beginning until the end. Yet, assessment instrument used is checklist with several indicators of empathy attitude which is developed from empathy aspect of Willams, Berard \& Barrchard (2005). To be able to get data validity, several techniques are used based on discussion with teachers of history subject in Senior High School in Banyumas and deeper talks with experts. Triangulation technique of data source is also used to enhance the validity by checking the data from several different sources due to the same problem. Data analysis is held by analysis interactive technique. Then, data is analyzed using independent samples t-test through SPSS.

\section{Result and Discussion}

Treatments used for this experiment class consist of initial action, repetition, and recall. Treatments use six values of empathy attitude in Babad Banyumas. These values are arranged by indicators of empathy attitude and the influence will be seen after posttest in the end of experiment. The details of indicators can be seen in table 1. 


\begin{tabular}{|l|l|}
\hline \multicolumn{1}{|c|}{ Sympathy Indicators } & \multicolumn{1}{c|}{ Babad Banyumas values } \\
\hline Listening to other people talk & Politeness \\
\hline Accepting other point of view & Respect, egalitarian \\
\hline Being sensitive to other people's feelings & Compassion, mutual help, forgiving. \\
\hline
\end{tabular}

Table 1. Sympathy indicators

Normality test through Kolmogorov Smirnov analysis technique is used in prerequisites test. Besides, homogeneity test is using Levene's Test for Equality of Variances as analysis technique through SPSS 15. Each result of normality test and homogeneity test show $\rho>$ 0,05 , which means the data used is normal (population representation) and homogeny (have the same variant).

Then, hypothesis test is conducted using independent samples t-test to compare mean of group between experiment class and control class. Based on hypothesis test result, it can be concluded that: (1) when pretest is held, experiment class hasn't gotten any treatment yet. The result shows that there is no difference in empathy attitude between experiment class and control class. (2) when posttest is held, experiment class has already experienced the treatment. The result shows that there are differences in empathy attitude between experiment class and control class. The details of hypothesis can be seen in table 2 .

\begin{tabular}{|c|c|c|c|}
\hline Test & Class & M & $\rho$ \\
\hline \multirow{2}{*}{ Pretest } & Experiment & 5.96 & \multirow{2}{*}{0.419} \\
\cline { 2 - 3 } & Control & 5.56 & \\
\hline \multirow{2}{*}{ Posttest } & Experiment & 8.55 & \multirow{2}{*}{0.003} \\
\cline { 2 - 3 } & Control & 6.80 & \\
\hline
\end{tabular}

Table 2. The Result of Hypothesis

Based on hypothesis test in table 1, it can be showed that mean score of empathy attitude of experiment class is increasing from 5,96 to 8,55. From this result, there are several discoveries. These discoveries have been identified as an improvement factor of student's empathy attitude.

First, when the treatment is conducted, several students give responses and say that the story in Babad Banyumas is similar to their daily life. It is caused by their background which is appropriate to Babad Banyumas. The character in Babad Banyumas is described as the student's characteristics. In example, they learn about Ki Dipati who likes to help others. Besides, several students point to some characters that are similar to them visually as well and the characters are devoted to elderly. A lot of students who give good feedbacks by asking about the character of the story for further information. This means visual and graphic concept which is similar to real life can attract students to reflect on specific character in the story. In the other hand, the same cultural background help students to understand the plot story itself. For the researcher, similar cultural setting between the story and subject helps to gain the goal of this study.

Second, when the experiment is conducted, the learning subject used is a character of Raden Baribin. Treatment is given by telling about Raden Baribin who was driven out from his kingdom and no one who was willing to help. Almost of all students express their sincerity for Raden Baribin with sadness cue. Several students give feedbacks such as a question about Raden Baribin's condition that was already starving day by day. After the treatment was delivered, students show an improvement of sympathy and empathy by doing a lot of research's indicators. They help their friend who doesn't bring any pen and ask their 
friend to join in a game (especially who doesn't have any friends before). Moreover, a student comes to erase the whiteboard without any convenience so that teacher can use it again.

Third, when the treatment is conducted, students seem to enjoy the story since the teacher includes some videos, music, and pictures. During the treatment, students are active in giving feedbacks like questions and statements toward Babad Banyumas story. Students are not engaging in boredom during ten minutes treatment. They are enthusiast when listening to the story. When the bell of switched lesson is ringing, students are still craving for more stories.

Fourth, students look like that they are having more comprehension to act or react toward real situation which is similar to the story. Repetition and recall give students an extra time to understand the story better. When repetition and recall are held, students are active in giving a lot of questions. This means recall lets students to build retention of knowledge toward empathy attitude which can be implemented in some sort of real phenomenon.

Based on observation of behavior which is supported during experiment conducted, mean score of experiment class is increasing from 5,96 in pretest to 8,55 in posttest. As many as 48 students or $80 \%$ students show that there is an improvement of empathy attitude after treatment is held, while 12 students or $20 \%$ students haven't showed any improvement.

Based on conducted observation, most students showed anti social behaviors such as apathetic toward others, avoiding friends with different background, and ignorant whether they see dirty blackboard or not. There was also bullying toward students who are considered as the weakest, the ugliest, and else. After treatment was applied, empathy attitude appears in students. These attitudes like caring in others and initiative idea to help erasing whiteboard have been developed so far. Moreover, bullying has been decreased significantly. Some of empathy attitudes are categorized as appearance and some others are enrichment.

By using Babad Banyumas in classroom, it can lead to experience and knowledge that will be used by students to enhance their empathy attitude. It is strengthened by discovery of researcher. Students who join in treatment less than six times (once or twice) will not express any improvement of empathy. Presence is one of the essential factor which influences toward information and knowledge in students. So, student's presence is identified as one of big impacts that can help students to grow their empathy, while it has been already one of important thing in education.

Students who attend less treatment show an ignorant attitude toward others who already express the actual knowledge from Babad Banyumas. In example, one of Babad Banyumas stories is brought by helping other people. After action, repetition, and recall phase, there are several tendencies in classroom. Students who interpret the story of Babad Banyumas will help their friends happily, while others are ignorant about this.

After that, there are several things that are considered by researcher. One of picture visualizations must be interpreted as well. The discovery of researcher tells that students are focusing in visual learning. This fact influences on information analysis in students based on story teller. Several facial cues which are not properly recognized by students will give a little confusion. Thus, several students will ask and criticize the story.

In the other hand, Babad Banyumas that has been told in the beginning of teaching and learning process can be considered as one of subject in history class as well. It is because teaching and learning process of students is arranged in one fine theme and cannot be separated. Empathy attitude in Babad Banyumas, which is being new knowledge in the 
beginning of classroom activity, will be suitable subject in the next meeting, such as daily conversation or evaluation.

\section{Conclusion}

This research shows that the using of Babad Banyumas can influence student's empathy attitude in Senior High School in Banyumas. The influence is proved by improvement of mean score in experiment class, increasing from 5,96 to 8,55 with 0,003 of significance value in posttest of experiment and control class. The result shows that there are differences in student's empathy attitude between the ones who receive treatment and the others who don't get any treatment. From this result, it can be concluded that Babad Banyumas can improve student's empathy attitude.

Babad Banyumas can be used for teacher in teaching history to improve student's empathy attitude at school. Then, teacher can give maintenance program to defend the growth of empathy attitude based on habituation from Babad Banyumas. This program will be delivered effectively by getting any support from school in line with teaching and learning innovation held by the teacher in order to encourage students toward optimum development.

\section{Acknowledgments}

The author would like to thank all the participants for their support, especially Prof. Dr. Warto, M.Hum and Prof Dr. Sariyatun, M.Pd., M.Hum who give a lot of time for the author to guide and correct this research due to several advices and criticism.

\section{References}

1. Trubina, Iriana I. \& Braines, Anna A. Imp Ed. SHS Web of Conferences 29, 1 (2016)

2. Novikova, Nataliya. Comp Edu. SHS Web of Conference 29, 2 (2016)

3. Gukalenko, Olga V \& Borisenkov, Nadimir P. Edu Glob. SHS Web of Conferences 29, 1 (2016)

4. Karpov, Alexander., Kharin, Alexander \& Kharina, Olga. Edu Envy. SHS Web of Conferences 29, 1 (2016)

5. Noorden, et al. Emp Involv Bul Child. J Youth Adolescence, 44, 637 (2015)

6. Geng, Yaoguo., Xia, Dan \& Qin, Beibei. Emp Sca. Child Psychiatry Hum Dev 43, 501 (2012)

7. Hermanu Joebagio dalam Garvey, Brian \& Krug, Mary, MPSSM (Ombak, Yogyakarta, 2015).

8. Sugeng Priyadi, Sej Lok (Pustaka Pelajar, Yogyakarta, 2011)

9. Hutagalung, Inge. Func Int. SHS Web of Conferences 33, 3-5 (2017)

10. Sudraba, V., Martinsone, K. \& Amis, V. Chang Ind. SHS Web of Conferences 10, 2 (2014)

11. Naydenova, Irina S. \& Naydenova, Natalia N. Teac Port. SHS Web of Conferences 29, 3 (2016)

12. Goleman, Daniel, Social Intelligence: New Scie (Bantam Dell, New York, 2006) 